\title{
Impairment no setor público: particularidades das normas nacionais e internacionais*
}

\author{
Luiz Nelson Guedes de Carvalho** \\ Patrícia de Souza Costa*** \\ Alan Teixeira de Oliveira****
}

SumÁrio: 1. Introdução; 2. Mensuração de ativos, fair value e impairment test; 3. Órgãos normatizadores; 4. Comparação entre os pronunciamentos; 5. Considerações finais.

Summary: 1. Introduction; 2. Asset measurement, fair value and impairment test; 3. Standardizing bodies; 4. Statement comparison; 5. Final remarks.

Palavras-chave: Impairment; Ipsas; Gasb; fair value.

KEY WORDs: impairment; Ipsas; Gasb; fair value.

O impairment no setor público tem sido pouco discutido no meio acadêmico. Os órgãos normatizadores têm publicado pronunciamentos sobre o assunto, enquanto

\footnotetext{
* Artigo recebido em fev. e aceito em maio 2010.

** Mestre e doutor em controladoria e contabilidade pela Universidade de São Paulo. Endereço: Universidade de São Paulo, Faculdade de Economia, Administração e Contabilidade, Departamento de Contabilidade Atuária. Av. Professor Luciano Gualberto, 908, Edifício FEA 3 - Butantã CEP 05508-900, São Paulo, SP, Brasil. E-mail: lnelson@usp.br.

*** Mestre em ciências contábeis pelo Programa Multi e Inter Regional de Pós-Graduação em Ciências Contábeis da UnB, UFPB, UFPE. Ingressou no Programa de Pós-Graduação (Doutorado em Ciências Contábeis) da FEA/USP em 2008. Endereço: Universidade Federal de Uberlândia, Faculdade de Ciências Contábeis, Departamento de Ciências Contábeis. Av. João Naves de Ávila, 2121, Bloco F, sala 1F215 - Santa Mônica - CEP 38400-902, Uberlândia, MG, Brasil. E-mail: patricia@facic.ufu.br.

$\because \cdots: *$ Doutorando em controladoria e contabilidade pela Universidade de São Paulo (USP), mestrando em administração pública pela Fundação Getulio Vargas (Ebape/FGV), mestre em ciências contábeis pela Universidade Federal do Rio de Janeiro (UFRJ). Endereço: Departamento de Polícia Federal, Setor Técnico-Científico. Rua Hugo D’Antola, 95, $10^{\circ}$ andar - Lapa CEP 05038-090, São Paulo, SP, Brasil.
} 
muitas dúvidas surgem e permanecem sem resposta. Diante disso, este artigo analisa as particularidades de normas nacionais e internacionais balizadoras do impairment no setor público: o Gasb 42, os Ipsas 21 e 26 e a NBC T 16.10. Foram analisados aspectos relacionados ao conceito de impairment, à periodicidade de aplicação do teste, para quais ativos deve ser aplicado e o processo de reconhecimento, mensuração e evidenciação da perda por impairment. As principais divergências entre os pronunciamentos são: o Gasb 42 está baseado em princípios e não em regras; os critérios utilizados pelo Gasb 42 para cálculo do fair value são semelhantes àqueles usados pelos Ipsas 21 e 26 para cálculo do valor em uso; o valor de reposição é usado para cálculo do fair value no Gasb 42 e o valor de saída nos Ipsas; apenas o Ipsas 26 utiliza a figura da unidade geradora de caixa; o Gasb 42 não admite a reversão da perda por impairment e os Ipsas não se aplicam a bens reavaliados. Apesar da NBC T 16.10 já estar em vigor no Brasil, todos os ativos públicos e a depreciação precisam ser reconhecidos e mensurados antes da aplicação dessa norma.

Impairment in the public sector: particularities of Brazilian and international standards

Little discussion on impairment in the public sector has occurred in the academic context. Standardizing bodies have published pronouncements on this issue, but many doubts arise and remain unanswered. This article analyzes the particularities of Brazilian and international standards guiding impairment in the public sector: Gasb 42, Ipsas 21 and 26 and NBC T 16.10. The aspects analyzed were related to the impairment concept, the periodicity of applying the test, what assets it should be applied to and the recognition, measurement and disclosure process of impairment loss. The main divergences between the pronouncements are: Gasb 42 is based on principles instead of rules; the criteria Gasb 42 uses to calculate the fair value are similar to the criteria Ipsas 21 and 26 use to calculate the value in use; the replacement cost is used to calculate fair value in Gasb 42 and the outflow value in both Ipsas; only Ipsas 26 uses the figure of cash-generating unit; Gasb 42 does not permit the reversal of impairment loss and the Ipsas do not apply to revalued goods. Although NBC T 16.10 is already in force in Brazil, all public assets and depreciation need to be recognized and measured before this standard is applied.

\section{Introdução}

Este artigo analisa as particularidades de normas nacionais e internacionais balizadoras do impairment no setor público. Em 2003, o Governmental Accounting Standards Board (Gasb, 2003), órgão nos Estados Unidos responsável pela emissão de normas contábeis para o setor governamental, aprovou o Statement 42 accounting and financial reporting for impairment of capital assets and for insurance recoveries. Esse pronunciamento estabelece padrões para di- 
vulgação financeira e contábil do impairment test de ativos fixos do setor público. O International Public Sector Accounting Standards Board (Ipsasb) da International Federation of Accountants (Ifac, 2004, 2008) publicou dois pronunciamentos sobre o impairment no setor público: em 2004, o International public sector accounting standard (Ipsas) 21 Impairment of non-cash-generating assets, aplicado somente aos ativos que não são geradores de caixa; e, em 2008, o Ipsas 26 Impairment of cash-generating assets, para os ativos geradores de caixa.

Apesar do primeiro padrão internacional sobre a aplicação do impairment no setor público ter sido aprovado em 2003, no Brasil esse tema tem sido pouco debatido por acadêmicos e normatizadores. Uma iniciativa foi realizada pelo Ministério da Fazenda ao publicar a Portaria no 184 (Brasil, 2008), designando a Secretaria do Tesouro Nacional (STN) para desenvolver ações que visem promover a convergência entre as Normas Internacionais de Contabilidade publicadas pela Ifac e as Normas Brasileiras de Contabilidade aplicadas ao setor público (Nbcasp) editadas pelo Conselho Federal de Contabilidade (CFC). O CFC já publicou 10 Nbcasp. A NBC T 16.10 - Avaliação e mensuração de ativos e passivos em entidades do setor público — traz a necessidade de aplicação do teste de impairment para ativos do setor público (CFC, 2008b). Porém, esta norma não define os critérios para o reconhecimento, a mensuração e a evidenciação da perda por impairment.

No âmbito internacional, apenas quatro artigos foram publicados nos 40 periódicos listados no Portal Capes com o termo accounting no título (Capes, 2008). Esses artigos são teóricos e se limitam a descrever e exemplificar os pronunciamentos do Gasb e do Ifac. Alroy e Tal (2005) descrevem o Ipsas 21. Gauthier (2003), Anonymous (2004) e Chase e Royark (2006) descrevem o Gasb 42.

No Brasil, nenhuma pesquisa sobre o impairment no setor público foi publicada até nov. 2008 nos periódicos e nos anais de congresso classificados por nível de qualidade A, B e C na área de avaliação Administração, Ciências Contábeis e Turismo do sistema Qualis da Coordenação de Aperfeiçoamento de Pessoal de Nível Superior (Capes, 2008). A dissertação de Pigatto (2004) trata dos regimes contábeis no setor público, comentando brevemente sobre a necessidade do impairment nesse setor. Macêdo (2003) comenta sobre a necessidade de convergência entre as normas de contabilidade do setor público, mas não cita o impairment. O fato é que não foram encontradas pesquisas publicadas nos âmbitos nacional e internacional, com o objetivo de analisar e testar a efetividade das normas sobre o impairment no setor público. 
O Gasb 42 (2008) define o impairment como um significante e inesperado declínio na utilidade dos serviços de um ativo fixo. Para o Ipsas 21, o impairment representa uma perda no potencial de benefício econômico ou de serviço de um ativo, superior à depreciação econômica do bem (Ifac, 2004). Além das divergentes definições de impairment, outros pontos também carecem de debate: cabe o teste de impairment no setor público? Em caso positivo, como reconhecer, mensurar e evidenciar a perda por impairment? Para quais bens o teste seria aplicável? Em quais circunstâncias? Esta informação seria útil para quais usuários? Quais as dificuldades para aplicação do teste no setor público? Estas questões permanecem sem resposta na literatura contábil do setor público e poucas pesquisas com circulação nacional e internacional têm sido realizadas sobre tais temas.

Diante do exposto, o problema de pesquisa é: quais as particularidades das normas balizadoras do impairment no setor público - Gasb 42, Ipsas 21 e 26 e NBC T 16.10? Por meio de uma pesquisa exploratória, bibliográfica e documental são apresentadas comparações teóricas e simulações considerando dados hipotéticos do setor público.

Este artigo é uma orientação para a realização de futuras pesquisas voltadas para o estudo da aplicação do impairment no setor público e para a aplicação do teste na prática das entidades governamentais brasileiras.

O trabalho possui cinco seções. A próxima trata da relação entre a mensuração de ativos, especificamente a valor justo, e o impairment test, inclusive com algumas particularidades do reconhecimento e da mensuração de ativos no setor público. Na terceira seção é apresentada uma descrição dos órgãos normatizadores: Gasb, Ifac e CFC. A quarta seção traz uma comparação entre as normas nacionais e internacionais para a aplicação do teste no setor público. Os principais aspectos abordados na comparação são: identificação de quais ativos estão sujeitos ao teste de impairment, bem como quais entidades estão obrigadas a realizá-lo; reconhecimento, mensuração e evidenciação da perda por impairment. Na quinta seção são apresentadas as considerações finais e as recomendações para pesquisas futuras.

\section{Mensuração de ativos, fair value e impairment test}

O objetivo da realização do impairment test é assegurar que os ativos não estejam registrados contabilmente por um valor superior àquele passível de ser recuperado por uso ou por venda. Caso existam evidências claras de que ativos estão avaliados por valor não recuperável no futuro, deverá ser calculado o 
fair value do referido ativo. De maneira simplificada, a perda por impairment corresponde à diferença entre o valor contábil e o fair value do ativo, quando o segundo for menor.

A aplicação do impairment é dependente da adequada mensuração de ativos e passivos. O International Accounting Standards Board (Iasb) e o Financial Accounting Standards Board (Fasb) têm argumentado que informações contábeis imparciais e neutras são mais úteis para tomadores de decisões do que a informação baseada no princípio do conservadorismo (Gox; Wagenhofer, 2008). Consequentemente, segundo esses autores, os normatizadores tendem a ser favoráveis à mensuração de ativos e passivos pelo fair value (valor justo). "Valor justo é o montante pelo qual um determinado item poderia ser transacionado entre participantes dispostos e conhecedores do assunto, numa transação sem favorecimento" (Iudícibus e Martins, 2007:11). Valor justo pode ser interpretado como o valor de mercado, podendo ser valor de entrada ou de saída. Porém, quando o valor de mercado não existir, modelos matemáticos podem ser empregados para apurá-lo.

O valor justo está intimamente ligado ao conceito de ativo. "Ativos são prováveis benefícios econômicos futuros obtidos ou controlados por uma entidade particular como resultado de transações ou eventos passados" (Fasb, 1985:1). A característica comum possuída por todos os ativos - "potencial serviço" ou "o benefício econômico futuro" - representa a capacidade de fornecer serviços ou benefícios às entidades que os usam. Tal potencial poderá ser produtivo, quando o recurso for parte integrante das atividades operacionais da entidade, como, por exemplo, os ativos imobilizados (Iudícibus e Martins, 2007). O valor justo de um ativo fixo, por exemplo, pode ser identificado por meio da apuração do seu potencial produtivo ou do benefício econômico futuro que poderá ser gerado com o seu uso (CVM, 1995; Raupp e Beuren, 2006). Essa definição se aplica a todos os tipos de ativos, independente de ser um ativo público ou privado (CFC, 2008b).

A definição do modelo de mensuração dos ativos tem por objetivo apurar um valor para o ativo que exprima o "real" benefício econômico ou potencial de serviços. Por isso, para evitar distorções decorrentes da harmonização de critérios, geralmente não se adota um único critério para mensuração dos ativos. Para o imobilizado, por exemplo, seria mais adequado mensurar o potencial de serviço decorrente do uso. O benefício econômico que seria obtido com a venda de estoques, por exemplo, seria o critério mais adequado para mensurar o valor de um ativo mantido para venda.

A escolha do modelo de mensuração de ativo mais adequado visa reduzir a probabilidade de erro na representação do "real" valor do ativo. No 
entanto, mesmo sendo criterioso, esse processo de escolha, distorções entre o valor mensurado e o "real" podem ocorrer. Por esse motivo surgem alguns instrumentos contábeis para aproximar esses dois valores: correção monetária, reavaliação de ativos e o impairment (Silva et al., 2006).

O impairment representa um dano econômico, uma diminuição no benefício econômico esperado do ativo ou no seu potencial de serviço. Para identificá-lo, a empresa precisa aplicar o impairment test (teste de recuperabilidade do custo). Se o valor contábil do ativo for superior ao seu valor recuperável (por uso ou venda), registra-se uma perda por impairment (impairment loss).

O impairment está vinculado à mensuração de ativos pelo valor justo. Considerando uma empresa que possui a prática de avaliar os seus ativos a fair value, no momento da aquisição o ativo é registrado pelo valor justo. No final de um determinado período o fair value desse ativo depreciado é apurado novamente e confrontado com o fair value do período anterior. Se o resultado dessa reavaliação a valor justo for negativo, é aplicado o impairment test para identificar o valor da perda. Nesse contexto, o objetivo do impairment test é manter o ativo ao seu valor justo.

$\mathrm{O}$ conceito de impairment pode ser equiparado à regra do custo ou mercado, dos dois o menor, quanto ao caráter conservador (Gox e Wagenhofer, 2008). O conservadorismo tem influenciado a prática contábil há mais de 500 anos por meio da resumida regra: "não antecipe lucro, mas antecipe todas as despesas" (Watts, 2003:208). De acordo com o conservadorismo "os contadores devem divulgar o menor dos vários valores possíveis para ativos e receitas, e o maior dos vários valores possíveis de passivos e despesas" (Hendriksen e Van Breda, 1999:105). Portanto, os ativos líquidos e o lucro tendem a ser subavaliados quando da utilização de métodos conservadores de avaliação.

Surpreendentemente, nos últimos 30 anos a prática contábil tem se tornado mais conservadora, apesar da vigorosa oposição de muitos reguladores do mercado de capitais, normatizadores e acadêmicos (Watts, 2003). Para esse autor o impairment test é uma prática contábil essencialmente conservadora na medida em que reconhece uma perda por impairment somente se o ativo tiver um valor recuperável, pela venda ou uso, inferior ao seu valor contábil; caso contrário, mantém esse valor e não reconhece nenhum ganho (Gox e Wagenhofer, 2008). Essa perda pode até ser recuperada em períodos posteriores, desde que seja verificável ou realizada, mas sem ultrapassar o valor de ativo que estava contabilizado antes do seu reconhecimento.

Dessa forma, o impairment é um conceito conservador que procura manter o fair value do ativo, porém reconhecendo somente perdas, e não ganhos, 
decorrentes de uma variação no benefício econômico esperado do ativo ou no seu potencial de serviço.

\section{Reconhecimento e mensuração de bens públicos}

Para aplicação do impairment test é necessário que os ativos tenham sido adequadamente reconhecidos e mensurados. No setor público, este pré-requisito representa uma limitação para a realização do teste. Em decorrência de dificuldades de mensuração, alguns ativos não são reconhecidos nas demonstrações financeiras das entidades públicas brasileiras e, além disso, a depreciação dos ativos dessas entidades não é contabilizada.

Os bens públicos são de domínio nacional e pertencem à União, aos estados, ou aos municípios (Brasil, 2002, art. 98). Classificam-se em: bens de uso comum (rios, mares, estradas, ruas, praças); bens de uso especial (edifícios ou terrenos aplicados a serviço ou estabelecimento federal, estadual ou municipal como bibliotecas públicas, escolas públicas, postos de saúde); e bens dominicais (constituem o patrimônio das entidades públicas classificáveis como disponível, bens móveis, bens imóveis, bens de natureza industrial) (Brasil, 2002, art. 99; Iudícibus, Marion e Pereira, 2003). Embora todos os tipos de bens façam parte do conjunto dos bens públicos, que se utilizam de recursos da Lei Orçamentária para mantê-los e conservá-los, apenas os bens dominicais são incorporáveis ao patrimônio da administração pública, por meio de registros e escrituração contábil, como objeto de direito pessoal ou real de cada uma de suas entidades.

A razão para a não inclusão dos bens de uso comum e os de uso especial no patrimônio público seria a ausência de um valor de permuta (Lock e Pigatto, 2005), já que são inalienáveis (Brasil, 2002, art. 100) e difíceis de avaliar em moeda corrente.

A NBC T 16.10, emitida pelo CFC (2008b), expressa a vontade dos normatizadores de reconhecerem todos os bens públicos no patrimônio público das entidades governamentais. De acordo com o item 30 dessa norma, "os bens de uso comum, que absorveram ou absorvem recursos públicos, serão incluídos no ativo permanente da entidade responsável pela sua administração ou controle, estejam ou não afetos à sua atividade operacional". E, de acordo com o item 31, "a valorização dos bens de uso comum será efetuada, sempre que possível, ao valor de aquisição ou ao valor de produção e construção". Dessa forma, o entendimento dos normatizados é de que os bens de uso comum, os de uso especial e os dominicais devem ser reconhecidos no patrimô- 
nio público. E, ainda, eles devem sofrer o impairment test conforme expresso no item 25 dessa norma:

o reconhecimento inicial do ativo imobilizado deve ser contabilizado com base em seu valor de aquisição ou construção menos a depreciação, amortização ou exaustão acumulada segregada do montante acumulado de quaisquer perdas do valor que tenham sofrido ao longo de sua vida útil por impairment.

A Lei no 4.320 (Brasil, 1964), que determina normas gerais para elaboração e controle dos orçamentos e balanços da União, dos estados, dos municípios e do Distrito Federal, não constitui obstáculo à adoção das Normas Brasileiras de Contabilidade Aplicadas ao Setor Público (Macêdo, 2003). Por exemplo, essa lei não prevê a obrigatoriedade do cálculo da depreciação, entretanto, estabelece, no art. 108, §2º ${ }^{\circ}$ que as previsões para depreciação sejam computadas para efeito de apuração do saldo líquido das entidades com autonomia financeira e administrativa cujo capital pertença, integralmente, ao poder público (Nascimento, 2007). Considerando necessária a contabilização da depreciação para melhorar os processos de mensuração do ativo e accountability, o CFC (2008a) aprovou a NBC T 16.9 - depreciação, amortização e exaustão, com adoção de forma facultativa, a partir de nov. de 2008, e de forma obrigatória para os fatos ocorridos a partir de janeiro de 2010.

Percebe-se que existem vários obstáculos a superar quanto ao reconhecimento e à mensuração de ativos no setor público. O propósito deste artigo não é esgotar esta discussão, mas destacar que um efetivo impairment test só poderá ocorrer quando esses obstáculos forem superados.

\section{3. Órgãos normatizadores}

Dois órgãos internacionais e um nacional já emitiram normas sobre o impairment para o setor público. O Governmental Accounting Standards Board (Gasb) é uma organização independente que emite normas contábeis e financeiras para o governo municipal e estadual dos Estados Unidos. Criado em 1984 por um acordo entre a Financial Accounting Foundation (FAF) e 10 associações nacionais do governo, o Gasb é reconhecido pelo governo, pelos contadores e pelo mercado de capitais desse país como uma fonte oficial de princípios contábeis geralmente aceitos para o governo local e estadual (Generally accepted accounting principles - Gaap). O trabalho do Gasb é baseado nos pronunciamentos contábeis publicados pelo Financial Accounting Stan- 
dards Board (Fasb) para o setor privado. Sobre o impairment, o Gasb emitiu, em 2003, o Statement 42 Accounting and financial reporting for impairment of capital assets and for insurance recoveries.

O International Federation of Accountants (Ifac), criado em 1977, é uma organização independente, internacional e está localizada em Nova York. É composta por quatro boards que desenvolvem padrões sobre ética, auditoria, educação e padrões de contabilidade para o setor público. O foco deste último - o International Public Sector Accounting Standards Board (Ipsasb), criado em 1986 - é nos relatórios financeiros e contábeis necessários para governos federais, estaduais e municipais. O trabalho do Ipsasb é baseado nos pronunciamentos contábeis publicados pelo International Accounting Standards Board (Iasb) para o setor privado. O Ipsasb publicou dois padrões contábeis sobre o impairment. O International public sector accounting standard (Ipsas) 21, emitido em 2004, foi específico para os ativos não geradores de caixa. Já o Ipsas 26, emitido em 2008, baseado no International Accounting Standard (IAS) no 36, Impairment of Assets, emitido pelo Iasb (1998), trata dos ativos geradores de caixa.

O Conselho Federal de Contabilidade (CFC), criado em 1946, é uma autarquia especial de caráter corporativista, sem vínculo com a administração pública federal e orienta, normatiza e fiscaliza o exercício da profissão contábil no Brasil. Esse órgão (CFC, 2008c) constituiu em 2006 o Grupo Assessor das Normas Brasileiras de Contabilidade Aplicadas ao Setor Público (Nbcasps), com o objetivo de realizar um resgate, consolidação e necessária atualização da contabilidade pública no Brasil para as realidades nacional e internacional. Os objetivos desse grupo são: elaboração, discussão e apresentação de Projeto de Lei para alteração da Lei no 4.320/64; elaboração, discussão e edição das Nbcasp; tradução das Ipsas em conformidade com o pedido de autorização enviado à Ifac; convergência das Nbcasps às Ipsas até 2012.

A metodologia adotada pelo CFC (2008e) para construção das Nbcasps pode ser resumida em três etapas: discussão de minutas das normas em audiências públicas eletrônicas e em seminários com a participação dos profissionais de contabilidade e dos órgãos de representação da classe e das esferas governamentais; aprovação e publicação das normas; discussão, socialização e treinamento dos profissionais de contabilidade.

Foram realizados cinco seminários regionais e o seminário nacional ocorreu em outubro de 2008. O CFC já emitiu, disponibilizou em audiência pública e aprovou 10 Nbcasps. Entre essas normas, está a NBC T 16.10 - Avaliação e mensuração de ativos e passivos em entidades do setor público que trata da avaliação e da mensuração de ativos, incluindo a necessidade de 
aplicação do impairment test (CFC, 2008b). A Resolução no 1.137, que aprovou essa norma, entrou em vigor a partir de novembro de 2008, com adoção de forma facultativa, a partir dessa data, e de forma obrigatória para os fatos ocorridos a partir de janeiro de 2010.

\section{Comparação entre os pronunciamentos}

O Gasb 42 define impairment como um significante e inesperado declínio da utilidade dos serviços do ativo de capital (Gasb, 2003). O evento ou mudança que conduz ao impairment não é considerado normal e nem habitual, isto é, no momento em que o ativo foi adquirido, não foi prevista a ocorrência desse evento ou circunstância durante a vida útil do ativo de capital (Anonymous, 2004).

A definição de "significante e inesperado declínio" é subjetiva e exige julgamento profissional. O subjetivismo responsável é uma tendência do Fasb, que vem tentando migrar de uma postura baseada em regras para padrões orientados por princípios. Segundo a Securities and Exchange Commission (SEC, 2003), o fato dos princípios contábeis geralmente aceitos (Gaap) dos Estados Unidos não estarem orientados por princípios, tem gerado um grande número de regras detalhadas, orientações e especificações nos padrões, encorajando a fraude financeira. O Fasb e a SEC têm buscado os padrões baseados em princípios por causa dos escândalos contábeis (Benston, Bromwich e Wagenhofer, 2006). Infere-se que o Gasb está alinhado com essa tendência, emitindo pronunciamentos baseados em princípios que exigem a observância da essência sobre a forma das transações.

A utilidade dos serviços do ativo de capital representa a capacidade utilizável que na aquisição era esperada que o ativo fornecesse, e não o nível de utilização, que é a proporção da capacidade utilizável geralmente usada (Anonymous, 2004). A capacidade utilizada pode ser menor do que a capacidade utilizável original devido ao declínio na vida útil normal ou esperada ou por deterioração física, obsolescência ou mudanças da maneira de uso do ativo. A capacidade utilizável também pode ser diferente da capacidade de serviço máxima, quando a capacidade excedente é necessária por segurança, economia ou outras razões. Reduções na utilização ou aumento na capacidade excedente que não estão associadas com o declínio na utilidade dos serviços não são consideradas impairment (Anonymous, 2004).

O Ipsas 21 e o 26 definem impairment como a perda no benefício econômico futuro ou potencial de serviço de um ativo, acima ou abaixo do reconhecimento sistemático dessa perda ou potencial de serviço por meio da 
depreciação (amortização). Para um ativo gerador de caixa, reflete o declínio no benefício econômico futuro ou potencial de serviço incorporado a um ativo para a entidade que o controla (Ifac, 2008). Por exemplo: uma entidade pode estar utilizando apenas $25 \%$ da capacidade de seu estacionamento municipal. Esse ativo é mantido para propósitos comerciais, tendo sido estimado que exista retorno comercial quando forem usados $75 \%$ ou mais da capacidade do estacionamento. $\mathrm{O}$ declínio no uso não tem sido acompanhado por um significativo aumento nos preços das vagas. Assim, o ativo é reconhecido como deteriorado, porque seu valor contábil excede o seu valor recuperável.

Para um ativo não gerador de caixa, o impairment reflete o declínio na utilidade de um ativo para a entidade que o controla (Ifac, 2004). Por exemplo: uma entidade pode ter uma instalação construída com propósito de ser um depósito militar. Porém, esse está longe de ser o seu uso. Por causa da natureza especializada dessa instalação e de sua localização, é improvável que o ativo possa ser arrendado ou vendido. Assim, o ativo é reconhecido como deteriorado, pois não é capaz de fornecer para a entidade o fluxo de caixa decorrente do arrendamento ou da venda do ativo e tem pouca ou nenhuma utilidade para contribuir com o alcance de objetivos da entidade.

Na NBC T 16.10, o impairment (redução ao valor recuperável) representa "o ajuste ao valor de mercado ou de consenso entre as partes para bens do ativo, quando esse for inferior ao valor líquido contábil" (CFC, 2008b:3).

\section{Aplicáveis para quais entidades?}

O Ipsas 21 e o Ipsas 26 se aplicam a todas as entidades do setor público, exceto as Government Business Enterprises (GBEs). São classificadas como GBEs as empresas controladas por entidades do setor público, mas que podem contratar em seu próprio nome, possuem fins lucrativos e não dependem de recursos governamentais.

O Gasb 42 se aplica a todas as entidades governamentais locais e estaduais, incluindo aquelas com propósitos gerais; autoridades e corporações de benefício público; sistemas públicos de aposentadoria de empregados; serviços de utilidade pública, tais como: hospitais, outros fornecedores de serviços de saúde, faculdades e universidades.

O CFC é sucinto ao afirmar apenas que a NBC T 16.10 "estabelece critérios e procedimentos para a avaliação e mensuração de ativos e passivos integrantes do patrimônio de entidades do setor público" (CFC, 2008b). 


\section{Aplicáveis para quais ativos?}

O Gasb 42 restringiu a aplicação do impairment test apenas para capital assets inclusive aqueles que estejam segurados (quadro 1). Capital assets (ativos de capital) são ativos tangíveis ou intangíveis usados nas atividades operacionais da entidade e têm vida útil superior a um exercício, incluindo: terrenos, prédios, veículos, máquinas, equipamentos, obras de arte e infraestrutura (Robbins e Baldwin, 2002). De acordo com o Gasb 42 (2008), os terrenos são considerados ativos de capital separados dos prédios e melhorias, devendo ser avaliados separadamente para fins de impairment.

Por outro lado, o Ifac $(2004,2008)$ separa os ativos em dois grupos para fins de aplicação do teste. O Ipsas 21 é aplicável para ativos não geradores de caixa e o Ipas 26 para aqueles gerados de caixa, cujo principal objetivo é dar retorno comercial. De acordo com esses pronunciamentos, um ativo gera retorno comercial quando é empregado de uma maneira consistente com a adotada por uma entidade com fins lucrativos. Dessa forma, uma entidade que mantém um ativo gerador de caixa espera obter entradas positivas de caixa e retorno comercial superiores ao risco envolvido na manutenção desse ativo. Um hospital público, por exemplo, pode possuir alguns ativos geradores de caixa, embora o propósito da maioria dos ativos não seja este. O hospital pode organizar uma estrutura, uma ala ou um prédio específico para atender pacientes que possuem convênio médico particular ou que efetuam os pagamentos em moeda. Assim, os ativos geradores de caixa, numa entidade do setor público, podem funcionar independentemente de ativos não geradores de caixa.

$$
\text { Quadro } 1
$$

Ativos que podem sofrer o impairment test

\begin{tabular}{|c|c|}
\hline Norma & Tipos de ativo \\
\hline Gasb 42 & Ativos de capital, inclusive os que estão segurados \\
\hline Ipsas 21 & $\begin{array}{l}\text { Todos os ativos não geradores de caixa, exceto: ativos originados de contratos de } \\
\text { construção, inventários, ativos financeiros, investimentos em propriedade mensurados } \\
\text { a fair value, propriedades, máquinas e equipamentos não gerados de caixa que são } \\
\text { mensurados por valores reavaliados }\end{array}$ \\
\hline Ipsas 26 & $\begin{array}{l}\text { Todos os ativos geradores de caixa, exceto: ativos originados de contratos de } \\
\text { construção, inventários, ativos financeiros, investimentos em propriedade mensurados } \\
\text { a fair value, propriedades, máquinas e equipamentos não gerados de caixa que } \\
\text { são mensurados por valores reavaliados, ativos tributários diferidos, benefícios a } \\
\text { empregados, ativos intangíveis avaliados a fair value, goodwill, ativos biológicos }\end{array}$ \\
\hline NBC T 16.10 & Não especifica \\
\hline
\end{tabular}


Para o Ipsas 26, o impairment test é aplicável tanto a um ativo em particular quanto a uma unidade geradora de caixa (UGC). Na impossibilidade de determinar o montante recuperável de um ativo individual, será determinado o montante recuperável dos ativos que compõem a UGC. Uma UGC representa o menor grupo identificável de ativos mantidos com o objetivo primário de gerar retorno comercial e que geram entradas de caixa de uso contínuo. Essas entradas e equivalentes de caixa são em grande parte independentes daquelas geradas por outros ativos ou grupos de ativos, tendo sido recebidas de fonte externa (Ifac, 2008).

O Ipsasb considerou que o Ipsas 21 é aplicável para ativos individuais, e que a adoção do conceito de UGC é desnecessária porque é possível identificar o potencial de serviço de cada ativo não gerador de caixa individualmente e essa adoção introduziria demasiada complexidade na contabilização do impairment desses ativos (Ifac, 2008).

O Gasb 42 e a NBC T 16.10 não tratam da figura da UGC, permitindo a realização do impairment test somente para ativos individuais.

São excluídos do escopo do Ipas 26 os ativos intangíveis que são regularmente reavaliados a fair value e o goodwill (Ifac, 2008). O Ipsasb concluiu que o goodwill não deve estar no escopo desse padrão porque ainda não foi emitido nenhum Ipsas sobre combinações de entidades (Ifac, 2008). O órgão considera que questões específicas relacionadas ao setor público surgirão quando combinações de entidades desse setor se concretizarem, em particular, se uma entidade pública puder ser identificada como compradora. Para esse órgão, os usuários necessitam de um padrão contábil nacional ou internacional sobre o impairment do goodwill, com a alocação do goodwill para UGCs e o teste para impairment de UGCs com o goodwill. Assim, exceto para o goodwill e para os ativos intangíveis regularmente reavaliados a fair value, o Ipsas 26 se aplica a todos os ativos intangíveis e tangíveis geradores de caixa. Por outro lado, todos os ativos intangíveis não geradores de caixa são incluídos do escopo do Ipsas 21.

Infere-se, a partir da restrição do Gasb 42 à aplicação do impairment somente para ativos de capital, que os ativos tangíveis e os intangíveis de longo prazo utilizados na atividade operacional da entidade estão incluídos no escopo desse pronunciamento. Já a NBC T 16.10 não especifica para quais ativos o impairment test é aplicável.

\section{Periodicidade de aplicação do impairment test}

O Ipsas 26 requer que uma entidade efetue o impairment test de um ativo intangível que ainda não esteja disponível para uso ou com vida útil indefinida 
no mínimo anualmente, independentemente da existência de indicadores de deterioração. O Ifac (2008) considera que a capacidade desse ativo em gerar benefícios econômicos futuros ou potencial de serviço suficiente para cobrir o seu valor contábil é mais incerta.

Para os demais ativos, tanto o Ipsas 21 quanto o Ipsas 26 determinam que, somente se houver um indicador de deterioração do ativo, a entidade deve, formalmente, efetuar o impairment test para verificar se uma perda por impairment efetivamente ocorreu. Esses procedimentos são idênticos aos descritos no Gasb 42 para os ativos de capital.

A NBC T 16.10 não especifica a periodicidade de aplicação do impairment test.

\section{Reconhecimento do impairment por meio de indicadores}

De uma maneira simplificada, a apuração da perda por impairment é efetuada em três etapas: a primeira etapa é a identificação ou reconhecimento da perda, na qual se verifica, por meio de indicadores internos ou externos, se ocorreram fatos geradores para o teste (quadro 2); em caso positivo, na segunda etapa comparase o valor contábil do ativo com o seu valor recuperável; e, por último, se o valor recuperável for inferior ao valor contábil, registra-se uma perda por impairment.

Quadro 2

Exemplos de indicadores do impairment test

\begin{tabular}{|ll|}
\hline Norma & Indicadores de impairment \\
\hline Gasb 42 & - Danos físicos \\
& - Alteração da legislação \\
& - Desenvolvimento tecnológico ou obsolescência \\
& - Alteração na maneira ou na expectativa de duração do uso \\
& - Interrupção de construção \\
\hline Insas 21 & Indicadores internos \\
& Danos físicos \\
& - Alteração na maneira ou na expectativa de duração do uso \\
& Evidência disponível de relatório interno que indica que a execução de serviço de um \\
& ativo é, ou será, significativamente pior do que o esperado \\
& Indicadores externos \\
& - Suspensão, ou suspensão próxima, da demanda ou necessidade por serviços fornecidos \\
& pelo ativo, embora o ativo ainda permaneça com o mesmo potencial de serviço \\
& - Significativa mudança de longo prazo com um efeito adverso sobre a entidade \\
&
\end{tabular}




\begin{tabular}{|ll|}
\hline Norma & Indicadores de impairment \\
\hline Ipsas 26 & Indicadores internos \\
& - Idem ao especificado no Ipsas 21 \\
& Indicadores externos \\
& - Declínio significativo no valor de mercado \\
& - Mudanças significativas de mercado, tecnológicas, econômicas e legais \\
& - Aumento nas taxas de juros ou outras taxas de retorno sobre investimento \\
\hline NBC T 16.10 & - Não especifica \\
\hline
\end{tabular}

No entanto, essas relações não são exaustivas, exigindo o julgamento profissional quanto ao melhor critério para reconhecer uma perda por impairment. A necessidade de efetuar o impairment test surge quando ocorre um desses indicadores.

De acordo com o Gasb 42, os indicadores de impairment são eventos ou mudanças nas circunstâncias que afetam o ativo de capital, indicando a eminência de impairment - e que é evidente ou conhecido pelo governo (Gasb, 2003). Nesse pronunciamento, indicadores comuns de impairment incluem (Anonymous, 2004):

- evidência de dano físico, como um prédio danificado por fogo ou enchente, quando o nível de dano é tal que esforços de restauração são necessários para restabelecer a utilidade do serviço fornecido pelo ativo de capital;

v ratificação ou aprovação de lei ou regulamento ou outras mudanças em fatores ambientais, que limitam ou reduzem o uso dos ativos de capital porque o ativo não satisfaz ou não pode ser mudado para satisfazer o requerido na nova lei ou regulamento. O impairment deve ser divulgado no momento em que o fato ocorre e não quando o efeito da mudança acontecer. Exemplos podem incluir proibição de tanques de armazenagem ou fábrica de tratamento de água que não satisfaça as novas exigências legais e a proibição da utilização de alguns ativos ou materiais;

v desenvolvimento tecnológico ou evidências de obsolescência, resultando em um ativo de capital com uso menos frequente ou nenhum. $\mathrm{O}$ equipamento de imagem de ressonância magnética, por exemplo, pode ser substituído por outro modelo mais popular ou que forneça um diagnóstico mais preciso. Outros exemplos são equipamentos de diagnóstico raramente usados porque novos equipamentos fornecem melhores serviços;

v uma mudança na maneira ou na expectativa de duração do uso do ativo de capital, tais como o fechamento de uma escola antes do fim de sua vida útil por causa de declínio no número de matrículas, o prédio de uma escola 
usado como um depósito ou o fechamento de uma rua antes do fim de sua vida útil por razões de segurança;

จ uma interrupção permanente na construção antes de completar um ativo, como por exemplo a parada na construção de um prédio por falta de recursos financeiros ou a interrupção devido à descoberta de uma espécie animal perigosa no local da construção.

O Gasb 42 destaca que a mudança na demanda por serviços do ativo de capital não é considerada um indicador em separado de impairment (Anonymous, 2004). Entretanto, essas mudanças na demanda devem ser causadas ou estar associadas aos indicadores de impairment. Nessas circunstâncias, os ativos de capital podem ser testados por impairment. Como exemplo, considere uma redução no número de matrículas em uma determinada escola. Se essa redução conduzir para o fechamento da escola, uma mudança na maneira ou na duração do uso, o teste de impairment deve ser efetuado. No entanto, se essa redução alterar uma condição de superlotação para uma na qual o número de alunos é adequado e isto não estiver associado com qualquer indicador de impairment, o teste não é requerido.

Com relação ao "declínio inesperado" constante na definição de impairment do Gasb 42, destaca-se que se os fatores causadores desse declínio forem previsíveis, devem ser incorporados à depreciação e não representam impairment (Wielenberg e Scholze, 2007). A depreciação representa o declínio no potencial de serviços dos ativos não correntes, em função de deterioração física gradual ou abrupta, consumo dos potenciais de serviços por meio de uso ou deterioração econômica por causa da obsolescência ou de mudança na demanda dos consumidores (Iudícibus, Marion e Pereira, 2003). Dessa forma, alguns indicadores do impairment test também são indicadores da depreciação e vice-versa. Por exemplo: obsolescência, deterioração ou dano físico, mudança na demanda dos consumidores que pode ser observada por meio da análise das variações orçamentárias. Porém, uma característica fundamental para diferenciar estes dois conceitos é a previsibilidade.

Wielenberg e Scholze (2007:3) argumentam que existe um trade off entre depreciação e impairment. A depreciação é uma "medida de perspectiva", determinada ex ante; auxilia na aproximação do valor contábil ao valor econômico do ativo. Por outro lado, o impairment é usado como um canal para transmitir informações sobre o desempenho do ativo durante a sua vida útil, especificamente, perdas por impairment transmitem informações sobre o desempenho ex post. Para esses autores, as transações com consequências de 
longo prazo devem ser reconhecidas no balanço patrimonial a fair value. Os accruals ex ante como a depreciação são necessários para estimular investimentos. E, accruals ex post como impairment ou reavaliação transmitem informações sobre os esforços gerenciais nos períodos posteriores ao investimento. Dessa forma, a depreciação, ao contrário da perda por impairment, é passível de previsão.

Os Ipsas 21 e 26 separam os indicadores de impairment em dois grupos: internos e externos. Os indicadores internos estabelecidos nesses pronunciamentos são semelhantes àqueles estabelecidos no IAS 36 para as empresas do setor privado, exceto pelo acréscimo de um indicador: a decisão de interrupção na construção de um ativo antes de estar completo ou em uma usual condição (Alroy e Tal, 2005). Para esses autores, essa situação é mais comum no setor público, mas também é relevante para o setor privado.

Os indicadores internos apresentados nos Ipsas 21 e 26 estão contidos na relação de indicadores do Gasb 42, exceto pela inclusão de um indicador: evidência disponível de relatório interno que indica que a execução de serviço de um ativo é, ou será, significativamente pior do que o esperado. Essas evidências incluem a análise das variações entre orçado e real. Relatórios internos podem indicar que um ativo não está tendo o desempenho esperado ou o seu desempenho está se deteriorando ao longo do tempo (Alroy e Tal, 2005). Como exemplo dessas evidências, pode-se citar: variações desfavoráveis entre os fluxos de caixa orçados para adquirir o ativo ou a necessidade de caixa subsequente para operar ou mantê-lo e os fluxos de caixa reais; fluxos de caixa líquidos reais, gerados pelo ativo, inferiores aos orçados e lucros ou fluxos de caixa líquidos, provenientes do ativo, inferiores aos orçados. Esses autores citam o exemplo de um relatório interno da Secretaria de Saúde sobre as operações de uma clínica localizada na zona rural poder indicar que uma máquina de raios-X usada nessa clínica está deteriorada porque os custos de manutenção da máquina têm excedido significativamente o custo originalmente orçado.

Os Ipsas 21 e 26 divergem quanto aos indicadores externos de impairment. Esses indicadores também são similares àqueles do IAS 36. Porém, no Ipsas 21 foram omitidos dois indicadores constantes no IAS 36: um aumento durante o período da taxa de juros de mercado ou outras taxas de retorno sobre o investimento, e esses aumentos provavelmente afetarão a taxa de desconto usada no cálculo do valor em uso de um ativo em uso e reduzirão significativamente o valor recuperável do ativo; e a indicação relacionada às circunstâncias sobre as quais o valor contábil do patrimônio líquido da entidade é maior do que o valor de suas ações no mercado (Alroy e Tal, 2005). 
Segundo esses autores, a razão para a primeira omissão é que o valor em uso de um ativo não gerador de caixa não pode ser determinado pelo desconto de um fluxo de caixa, pois este não existe. Com respeito à segunda omissão, esses autores argumentam que o valor de mercado é irrelevante para mensurar o patrimônio líquido de uma entidade pública.

Ao contrário do Gasb 42, o Ipsas 21 considera a suspensão ou a redução na demanda ou necessidade de serviços fornecidos por um ativo, embora o ativo ainda permaneça com o mesmo potencial de serviço, como um indicador externo em separado. Por exemplo: o fechamento de uma escola por causa da falta de demanda para serviços escolares causada pela mudança da população para outras áreas, sendo que esta tendência demográfica não se reverterá num futuro próximo; uma escola com capacidade para 1.500 alunos recebe apenas 150 matrículas - essa escola não pode ser fechada porque a escola mais próxima está a $100 \mathrm{~km}$ de distância. A escola não prevê um aumento nas matrículas. Quando a capacidade estabelecida era de 1.500 alunos, a entidade deve ter adquirido muito mais recursos do que o necessário para atender apenas aos 150 alunos matriculados.

Se um evento ou circunstância indicar que o ativo de capital pode estar deteriorado, mas o impairment test determinar que a deterioração não ocorreu, a estimativa usada no cálculo da depreciação - estimativa remanescente da vida útil e do valor residual — deve ser reavaliada e mudada, se necessário.

Apesar das divergências entre os três pronunciamentos quanto aos indicadores que devem ser considerados para avaliar se existe alguma indicação de desvalorização do ativo, essas relações não são exaustivas e a responsabilidade subjetiva do profissional é requerida na seleção do critério mais adequado para reconhecer uma perda por impairment.

Para identificar uma UGC, a entidade considera vários fatores, incluindo como os gestores monitoram as operações da entidade (por linha de produto, negócio, região) ou como os gestores tomam decisões sobre a continuidade ou a venda dos ativos e das operações da entidade. Por exemplo: o governo tem uma empresa de geração de energia elétrica. Essa empresa tem duas turbinas geradoras de energia e uma única planta industrial. No período corrente, a principal indústria da região foi fechada e a demanda por energia elétrica foi significativamente reduzida. Diante disso, o governo paralisou uma das turbinas. Como uma turbina não gera fluxo de caixa sozinha, a UGC é usada no impairment test da indústria elétrica como um todo.

Uma UGC deve ser identificada consistentemente de período a período para o mesmo ativo ou tipos de ativos, a menos que a mudança seja justificada. 


\section{Mensuração da perda por impairment — aspectos gerais}

Uma vez reconhecida a deterioração do ativo por meio da análise de indicadores, o próximo passo é efetuar o impairment test para verificar se a deterioração é efetiva e mensurar o valor da perda. No quadro 3 são comparados os principais conceitos envolvidos no processo de mensuração dessa perda.

Uma perda por impairment só deve ser reconhecida se a desvalorização do ativo for permanente. Apesar da maioria das desvalorizações ser considerada permanente, o governo pode fornecer evidências contrárias (Chase e Roybark, 2006). Por exemplo: uma escola pode ser fechada por um curto período, mas, com base em dados da população, pode ser planejada a reabertura em alguns anos.

Quadro 3

Conceitos relacionados à mensuração

\begin{tabular}{|c|c|c|c|}
\hline Termos & Gasb 42 & Ipsas 21 e 26 & NBC T 16.10 \\
\hline $\begin{array}{l}\text { Perda por } \\
\text { impairment }\end{array}$ & $\begin{array}{l}\text { Menor valor entre o } \\
\text { valor contábil e o fair } \\
\text { value }\end{array}$ & $\begin{array}{l}\text { Valor contábil excede o valor } \\
\text { recuperável }\end{array}$ & $\begin{array}{l}\text { Diferença entre o valor líquido } \\
\text { contábil do bem e o valor de } \\
\text { mercado ou de consenso, } \\
\text { com base em laudo técnico }\end{array}$ \\
\hline $\begin{array}{l}\text { Valor } \\
\text { contábil } \\
\text { líquido }\end{array}$ & $\begin{array}{l}\text { É o valor pelo qual um } \\
\text { ativo está reconhecido } \\
\text { no balanço depois da } \\
\text { dedução de toda } \\
\text { respectiva depreciação, } \\
\text { amortização ou exaustão } \\
\text { acumulada e } \\
\text { provisão para perdas }\end{array}$ & $\begin{array}{l}\text { É o valor pelo qual um ativo } \\
\text { está reconhecido no balanço } \\
\text { depois da dedução de toda } \\
\text { respectiva depreciação, } \\
\text { amortização ou exaustão } \\
\text { acumulada e provisão para } \\
\text { perdas }\end{array}$ & $\begin{array}{l}\text { O valor do bem registrado } \\
\text { na contabilidade, em } \\
\text { determinada data, deduzido } \\
\text { da correspondente } \\
\text { depreciação, amortização ou } \\
\text { exaustão acumulada }\end{array}$ \\
\hline $\begin{array}{l}\text { Valor } \\
\text { recuperável }\end{array}$ & Não utiliza & $\begin{array}{l}\text { Maior valor entre o fair value } \\
\text { menos os custos de venda e } \\
\text { o valor em uso }\end{array}$ & $\begin{array}{l}\text { Valor de mercado menos o } \\
\text { custo para a sua venda, ou o } \\
\text { valor que a entidade espera } \\
\text { recuperar pelo uso futuro de } \\
\text { um ativo nas suas operações, } \\
\text { o que for maior }\end{array}$ \\
\hline $\begin{array}{l}\text { Valor em } \\
\text { uso }\end{array}$ & Não utiliza & $\begin{array}{l}\text { Valor presente do potencial } \\
\text { de serviço remanescente de } \\
\text { um ativo }\end{array}$ & Não especifica \\
\hline
\end{tabular}

Continua 


\begin{tabular}{|llll|}
\hline Termos & \multicolumn{1}{c}{ Gasb 42 } & \multicolumn{1}{c|}{ Ipsas 21 e 26 } & \multicolumn{1}{c|}{ NBC T 16.10 } \\
\hline Fair value & Não define & $\begin{array}{l}\text { É o montante obtido na } \\
\text { venda de um ativo entre } \\
\text { participantes dispostos e } \\
\text { conhecedores do assunto, } \\
\text { numa transação sem } \\
\text { favorecimento }\end{array}$ & $\begin{array}{l}\text { Valor de mercado ou valor } \\
\text { justo: o valor pelo qual um } \\
\text { ativo pode ser intercambiado } \\
\text { ou um passivo pode ser } \\
\text { liquidado entre partes } \\
\text { interessadas que atuam em } \\
\text { condiç̃es independentes e } \\
\text { isentas ou conhecedoras do } \\
\text { mercado }\end{array}$ \\
& & Não aplicável & Não especifica \\
Bens & Aplicável & Permitida & Não especifica \\
reavaliados & & & \\
Reversão & Não é permitida & &
\end{tabular}

\section{Gasb 42 - Mensuração da perda por impairment}

Na figura 1 são apresentadas as etapas necessárias para reconhecimento e mensuração da perda por impairment. O valor contábil líquido é o custo de aquisição deduzido da depreciação e da perda acumuladas por impairment (quadro 3). Além dessa representação do valor contábil líquido, o Gasb 42 permite substituir o custo de aquisição pelo valor reavaliado do bem ou pelo valor do bem após o registro de uma perda por desvalorização anterior. Nem sempre o valor reavaliado será igual ao valor de mercado, devido à possibilidade de ocorrência de despesa direta incremental para se desfazer do ativo. Dessa forma, se o valor em uso do ativo ou UGC for inferior ao seu valor reavaliado, após aplicar as determinações relativas à reavaliação, a entidade deve verificar se o ativo apresenta parcela não recuperável.

O Gasb 42 não define o termo fair value, porém considera o valor de reposição do ativo de capital como proxy do valor justo. Apesar do valor dessa perda resultar do confronto entre o valor contábil líquido e o fair value do ativo, para o Gasb 42, a escolha do método para mensurar o impairment é dependente da continuidade ou não de uso do ativo. O impairment de ativos de capital que não serão mais usados pela entidade pública e de construções paralisadas deve ser divulgado pelo valor contábil líquido ou o fair value, dos dois o menor. 
Figura 1

Etapas do reconhecimento e mensuração do impairment - Gasb 42

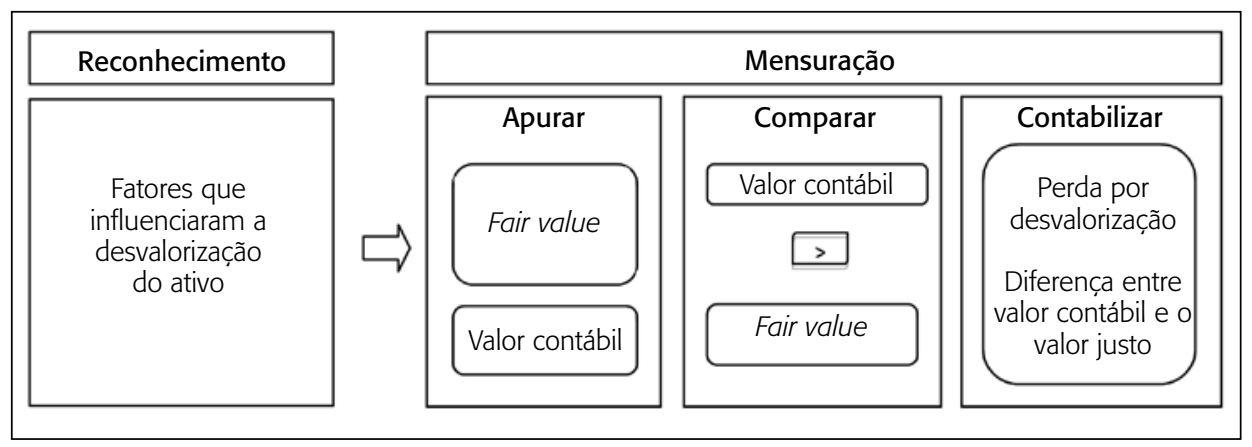

Para os ativos de capital que continuarão a ser usados pela entidade pública, a perda por impairment deve ser mensurada por um dos três métodos apresentados no quadro 4. A escolha entre os métodos deve ser baseada nos indicadores de impairment.

Quadro 4

Métodos para cálculo da perda por impairment conforme o Gasb 42.

\begin{tabular}{|ll|}
\hline Indicador de impairment & Método para cálculo da perda por impairment \\
\hline Dano físico & Restauração dos custos \\
Mudanças legais ou ambientais & Unidades de serviço \\
Desenvolvimento tecnológico ou obsolescência & Unidades de serviço \\
Mudança na maneira de uso ou na duração da & Unidades de serviço ou custo de reposição deduzido \\
vida útil do bem & da depreciação \\
\hline
\end{tabular}

A seguir são apresentados três exemplos de como mensurar e evidenciar o impairment de ativos de capital. Destaca-se que os eventos são não usuais e não controláveis pelos gestores, bem como significantes e inesperados.

O impairment derivado de dano físico geralmente deve ser mensurado pelo método de restauração do custo. Por esse método, o valor do impairment é derivado de uma estimativa de custo para restaurar a utilidade do ativo de capital. Na tabela 1 tem-se o exemplo de um prédio administrativo de uma universidade que foi danificado por um vendaval (dano físico). Esse prédio foi construído em 2000 por R \$ 28 milhões, com vida útil estimada de 30 anos. Em 2007, após sete anos de utilização, um vendaval atingiu o prédio causando danos estruturais importantes. O custo de reparo para recolocação do prédio em 
condições de uso é de $\mathrm{R} \$ 4,5$ milhões, sendo $\mathrm{R} \$ 3,5$ milhões capitalizados e o restante usado para demolição e limpeza. O prédio era segurado e o prêmio de seguro a ser recuperado é de $\mathrm{R} \$ 2,5$ milhões.

Tabela 1

Método da restauração do custo

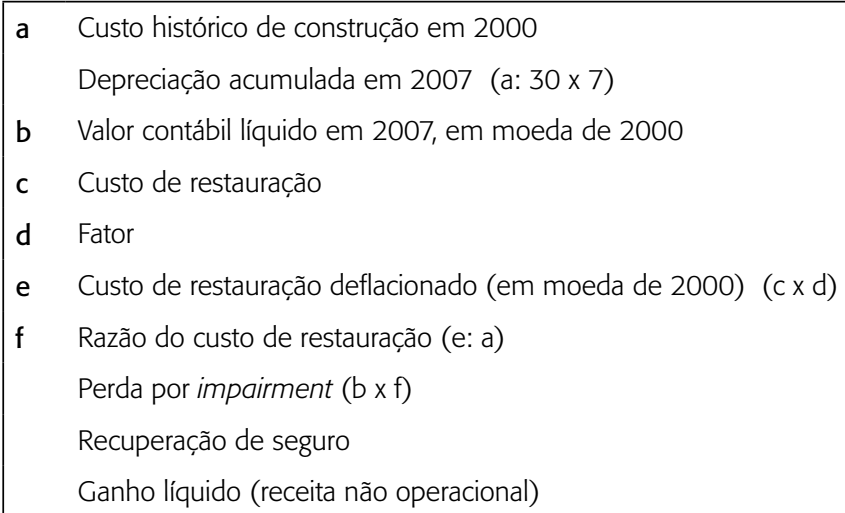

O método de restauração do custo requer a aplicação de um quociente de dano sobre o valor contábil líquido do ativo de capital para determinar a parcela relativa desse ativo que deve ser baixada por impairment. Esse quociente é calculado pela divisão do custo de restauração capitalizado pelo valor de custo do ativo (ambos em moeda de mesmo poder aquisitivo). Os custos de demolição e limpeza devem geralmente ser considerados custos não capitalizados, isto é, devem ser excluídos dos custos de restauração. A cobertura de seguro só pode ser reconhecida quando realizada ou realizável.

A contabilização da perda por impairment e do ganho líquido é feita separadamente (tabela 2). O ganho após a cobertura de seguro de $\mathrm{R} \$ 318,208$ mil deve ser contabilizado como uma receita não operacional.

Tabela 2

\section{Contabilização da perda por impairment}

\begin{tabular}{|lcc|}
\hline & Débito $-\$$ & Crédito $-\$$ \\
\hline $\begin{array}{l}\text { Baixa de ativo de capital (despesa operacional) } \\
\text { a) edifícios }\end{array}$ & 2.181 .792 & \\
$\begin{array}{l}\text { Caixa } \\
\text { a) baixa de ativo de capital (despesa operacional) }\end{array}$ & 2.500 .000 & \\
\hline
\end{tabular}




\begin{tabular}{|lcc|}
\hline & Débito - $\$$ & Crédito $-\$$ \\
\hline Receita não operacional & & 318.208 \\
Edifícios & 3.500 .000 & \\
Despesa com limpeza e demolição & 1.000 .000 & \\
a) caixa & & 4.500 .000 \\
\hline
\end{tabular}

O segundo método para cálculo da perda por impairment é o das unidades de serviço. Esse método é indicado em casos de mudanças legais ou ambientais, desenvolvimento tecnológico ou obsolescência e mudança na maneira de uso ou na duração da vida útil do bem. Este método isola o custo histórico da utilidade do serviço do ativo de capital que não pode ser usado devido ao evento de impairment ou mudanças nas circunstâncias. O montante do impairment é determinado pela avaliação do serviço fornecido pelo ativo de capital - a quantidade máxima ou o total estimado de unidades de serviço ao longo da vida útil do ativo - antes e após o evento ou mudança nas circunstâncias. Por último, deve-se aplicar o percentual de mudança em unidades sobre o valor contábil do ativo.

Sob a perspectiva desse método, o valor presente do serviço potencial remanescente do ativo é determinado por meio da redução dos custos correntes desse serviço antes do teste de impairment para comparação com a redução do número de unidades de serviço esperado do ativo. Como na abordagem da restauração do custo, o custo corrente de substituição do serviço potencial remanescente do ativo é normalmente definido como o custo depreciado da reprodução ou reposição do ativo antes da realização do teste, o que for menor.

A tabela 3 apresenta o exemplo de uma central de impressão adquirida em 1998 por R\$ 40 milhões. É estimada uma vida útil de 10 anos e uma produção de 40 milhões de cópias ao longo da vida útil. Em 2003, uma das funções do sistema não funcionava como o esperado provocando uma redução de $25 \%$ na capacidade da central nos cinco anos de serviços remanescentes. O custo de reposição de uma central em 2003 é de $\mathrm{R} \$ 45$ milhões. A redução permanente na capacidade produtiva da central é o indicador de impairment.

O valor recuperável do serviço é calculado com base na redução da capacidade produtiva da central em $25 \%$, ou seja, a empresa irá recuperar apenas $75 \%$ do serviço estimado ( $\mathrm{R} \$ 16,875$ milhões). Cabe destacar que neste método não é mencionada a necessidade ou a obrigação de efetuar ajustes pela inflação, o que pode ser considerado uma falha.

A perda por impairment é contabilizada com um débito na conta de despesa operacional e um crédito na conta do ativo de capital no valor de R\$ 3,125 milhões. 


\section{Tabela 3}

\section{Método das unidades de serviço}

\begin{tabular}{|c|c|c|}
\hline \multirow[t]{2}{*}{ a } & Custo de aquisição em 1998 & 40.000 .000 \\
\hline & Depreciação acumulada em 2003 (a:10 x 5) & 20.000 .000 \\
\hline$b$ & Valor contábil líquido em 2003, em moeda de 1998 & 20.000 .000 \\
\hline c & Custo de reposição & 45.000 .000 \\
\hline & Depreciação acumulada (c: 10 × 5) & 22.500 .000 \\
\hline d & $\begin{array}{l}\text { Custo de reposição depreciado antes do ajuste das unidades remanescentes de } \\
\text { serviço }\end{array}$ & 22.500 .000 \\
\hline e & Valor recuperável do serviço ( $\mathrm{d} \times \mathrm{75} \%)$ & 16.875 .000 \\
\hline & Perda por impairment $(b-e)$ & 3.125 .000 \\
\hline
\end{tabular}

O terceiro método, denominado custo de reposição deduzido da depreciação, é indicado quando ocorrer mudança na maneira de uso na duração da vida útil do ativo. O custo corrente para repor o nível corrente de serviço do ativo de capital é estimado. Este custo é depreciado para refletir o fato de que o ativo de capital não é novo, e então é deflacionado para estar em moeda de mesmo poder aquisitivo do custo histórico.

A tabela 4 traz o exemplo de mudança significativa no modo de utilização de uma escola construída em 2001. O custo de construção da escola foi de R \$ 10 milhões com vida útil estimada de 50 anos. No início de 2007, ocorreu uma queda nas matrículas escolares motivada pela migração das indústrias locais para outras cidades, provocando o fechamento da escola. Por esse motivo, a escola é convertida num depósito público, uma vez que não há expectativas de novas matrículas no futuro próximo. O custo de reposição estimado de um depósito público com a mesma capacidade de armazenagem da escola é de $\mathrm{R} \$$ 4, 2 milhões.

O processo de mensuração da perda por impairment de ativos que continuarão a ser usados pelo governo é apresentado na figura 2. 
Tabela 4

\section{Custo de reposição deduzido da depreciação}

\begin{tabular}{|clc|}
\hline a & Custo histórico de construção em 2001 & 10.000 .000 \\
b & Depreciação acumulada no final de $2006(\mathrm{a}: 50$ × 6) & 1.200 .000 \\
c & Valor contábil líquido em moeda de $2001(\mathrm{a}-\mathrm{b})$ & 8.800 .000 \\
d & Custo de reposição & 4.200 .000 \\
e & Depreciação acumulada $(\mathrm{d}: 50$ × 6) & 504.000 \\
f & Valor recuperável do serviço $(\mathrm{d}-\mathrm{e})$ & 3.696 .000 \\
g & Índice de inflação em 2001 & 100 \\
h & Índice de Inflação no final de 2006 & 125 \\
i & Fator de deflação $(\mathrm{g}: \mathrm{h})$ & $80 \%$ \\
j & Valor recuperável do serviço deflacionado (f x i) & 2.956 .800 \\
& Perda por Impairment $(\mathrm{c}-\mathrm{j})$ & 5.843 .200 \\
\hline
\end{tabular}

Figura 2

Processo de mensuração da perda por impairment de ativos que continuarão a ser usados

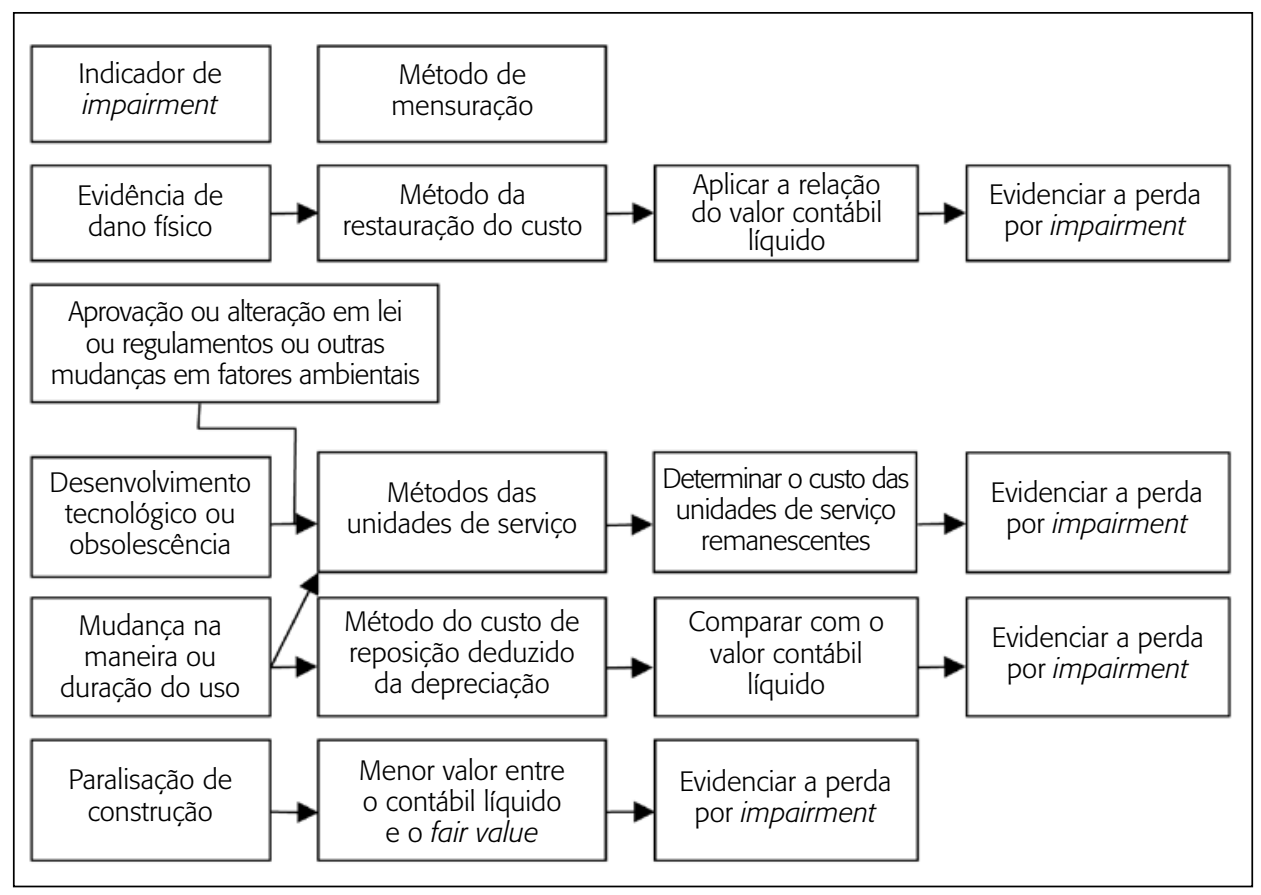

Fonte: Gauthier (2003:3, tradução livre). 
A perda por impairment reconhecida não pode ser revertida em períodos futuros, mesmo se os eventos ou circunstâncias que o causaram tenham mudado.

\section{Ipsas 21 e 26 - Mensuração da perda por impairment}

Na figura 3 são apresentadas as etapas necessárias para reconhecimento e mensuração da perda por impairment conforme os Ipsas 21 e 26.

Nos Ipsas 21 e 26, a perda por impairment é apurada quando o valor contábil excede o valor recuperável do ativo. O valor recuperável é o maior valor entre o fair value, deduzido dos custos de venda, e o valor em uso.

O valor contábil é o custo de aquisição deduzido da depreciação acumulada e as perdas acumuladas por impairment (quadro 3). Ao contrário do exposto no Gasb 42, os Ipsas não admitem a aplicação do impairment em ativos sujeitos à reavaliação.

Não é necessário determinar sempre, o valor em uso e o fair value de um ativo. Se um desses valores exceder o valor contábil líquido, o ativo não está deteriorado e não é necessário estimar o outro valor. Quando houver dificuldade para estimar de maneira confiável o fair value de um ativo, podese usar o valor em uso como seu valor recuperável. Para muitos ativos não geradores de caixa no setor público, que fornecem continuamente serviços especializados ou bens públicos para a comunidade, o valor em uso do ativo é provavelmente maior do que seu fair value menos os custos de venda. Por outro lado, em casos de ativos mantidos para alienação, quando a percepção de inferioridade do valor em uso em relação ao valor líquido de venda for confiável, pode-se usar este como seu valor recuperável.

O fair value é o montante obtido na venda de um ativo entre participantes dispostos e conhecedores do assunto, numa transação sem favorecimento (Ifac, 2004, 2008). Contrapondo o Gasb 42, para o qual o fair value é o valor de reposição, para o Ipsas 21, o fair value é preço de mercado obtido no mercado de venda menos os custos para alienação. Exemplos de custos de venda são: custos legais, imposto de importação, custos de remoção e custos incrementais para colocar o ativo em condições de venda.

Quando o montante estimado para a perda por impairment for maior do que o valor contábil líquido do ativo, esse valor deve ser reduzido a zero com o correspondente reconhecimento da perda. Um passivo poderá ser reconhecido somente se outro Ipsas o exigir. Um exemplo é quando uma instalação construída com propósito militar não é usada mais e a lei exige a remoção de 
tais instalações. A entidade pode necessitar fazer uma provisão para custos de demolição se isso for exigido pelo Ipsas 19 Provisions, contingent liabilities and contingent assets.

Figura 3

Ipsas 21 e 26

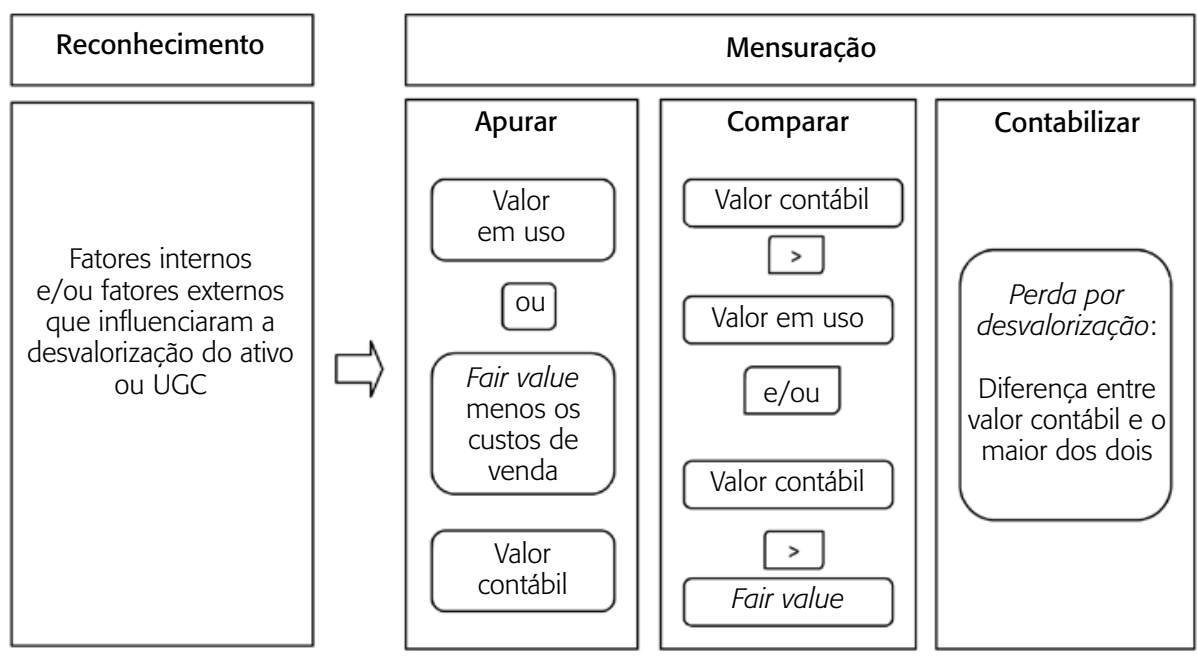

A entidade deve avaliar a cada exercício social se existe alguma indicação de que a perda por impairment reconhecida em períodos anteriores pode ter deixado de existir ou ter diminuído. Se existir qualquer mudança no indicador que baseou o impairment test, a entidade deve estimar o valor recuperável do ativo. Por exemplo: reestabelecimento da demanda ou necessidade dos serviços fornecidos pelo ativo, significantes mudanças de longo prazo no ambiente tecnológico, legal ou político, com efeito favorável para a entidade, evidências internas de que o desempenho do ativo irá melhorar significativamente. Dessa forma, uma perda por impairment reconhecida em períodos anteriores pode ser revertida somente se tiver ocorrido uma mudança nas estimativas usadas para determinar o valor recuperável do ativo desde a data em que a última perda foi reconhecida. Se este for o caso, o valor contábil líquido do ativo deve ser aumentado para o seu valor recuperável de serviço. Esse aumento é uma reversão da perda por impairment. Essa reversão não pode superar o valor contábil líquido do ativo antes de qualquer registro de perda por impairment. 
Após o reconhecimento de uma perda por impairment, inclusive do registro de reversões dessa perda, a depreciação (amortização) do ativo deve ser ajustada para alocar o valor contábil líquido revisado, menos o valor residual, sobre uma base sistemática ao longo da vida útil remanescente do ativo.

A reclassificação de um ativo de gerador de caixa para não gerador de caixa, ou o contrário, só deve ser feita quando ocorrer uma clara evidência de que tal reclassificação é apropriada. Uma reclassificação por si só não exige automaticamente um impairment test ou uma reversão da perda por impairment. Na verdade, é necessária a realização desses procedimentos quando, após a reclassificação, surge alguma indicação de que a perda por impairment pode ter deixado de existir ou ter diminuído.

Há circunstâncias em que as entidades do setor público podem decidir que é apropriado reclassificar um ativo gerador ou não gerador de caixa. Por exemplo: uma indústria de tratamento de efluente foi construída primeiramente para atender a uma indústria do estado a taxa comercial e o excesso de capacidade tem sido usado no tratamento de efluente de uma unidade de moradia social, para a qual nenhuma cobrança é feita. A indústria estadual foi recentemente fechada e, no futuro, o lugar será desenvolvido para propósitos de moradias sociais. Diante do fechamento da indústria estadual, a entidade do setor público decide reclassificar a indústria de tratamento de efluente para um ativo não gerador de caixa.

\section{Ipsas 21 - Aspectos específicos da mensuração da perda por impairment}

O valor em uso de um ativo não gerador de caixa é o valor presente do potencial de serviço remanescente de um ativo. Esse valor presente é determinado usando qualquer uma das seguintes abordagens ou métodos: custo de reposição deduzido da depreciação, restauração do custo e unidades de serviço. Essas abordagens são semelhantes aos métodos de apuração da perda por impairment apresentados no Gasb 42, inclusive na forma de cálculo. Duas principais divergências podem ser destacadas. Primeiramente, no Gasb 42 não é utilizada a figura do valor em uso. Assim, para o Gasb 42, o valor apurado com a utilização desses métodos é uma proxy para o fair value. Já no Ipsas 21, esses métodos são usados para apurar o valor em uso, uma vez que o fair value é um valor de saída. A segunda divergência é quanto à escolha entre o método mais apropriado para mensurar o valor em uso, que depende da disponibilidade de dados e da natureza do impairment tanto para o 
Gasb 42, quanto para o Ipsas 21. Porém, os métodos identificados pelo Gasb 42 e pelo Ipsas 21 como os mais apropriados para cada tipo de impairment são divergentes.

\section{Quadro 5 \\ Métodos para cálculo do valor em uso — Ipsas 21}

\begin{tabular}{|c|c|}
\hline Indicador de impairment & Método para cálculo da perda por impairment \\
\hline Dano físico & $\begin{array}{l}\text { Restauração do custo ou } \\
\text { custo de reposição deduzido da depreciação }\end{array}$ \\
\hline $\begin{array}{l}\text { Mudanças tecnológicas, legais ou de políticas } \\
\text { ambientais de longo prazo }\end{array}$ & Custo de reposição deduzido da depreciação \\
\hline $\begin{array}{l}\text { Mudança na maneira de uso, incluindo uma } \\
\text { identificada cessação da demanda }\end{array}$ & $\begin{array}{l}\text { Unidades de serviço ou } \\
\text { custo de reposição deduzido da depreciação }\end{array}$ \\
\hline
\end{tabular}

Para o Gasb 42, o impairment derivado de dano físico geralmente deve ser mensurado pelo método de restauração do custo, enquanto o Ipsas 21 indica também o custo de reposição deduzido da depreciação. Para o indicador de mudanças tecnológicas, legais ou de políticas ambientais, o Gasb 42 indica o método das unidades de serviço como o mais apropriado, enquanto o Ipsas 21 indica o custo de reposição deduzido da depreciação. Quanto ao impairment decorrente de mudança na maneira de uso do ativo, o método indicado, de maneira unânime, é o custo de reposição deduzido da depreciação.

\section{Ipsas 26 - Aspectos específicos da mensuração da perda por impairment}

O valor recuperável é determinado para um ativo individual, a menos que o ativo não gere entradas de caixa independentes de outros ativos ou grupos de ativos. Nesse caso, o valor recuperável é determinado para uma UGC para a qual o ativo pertence, a menos que: o fair value menos os custos de venda do ativo seja maior do que o valor contábil líquido ou se o ativo for parte da UGC, mas for capaz de gerar entradas de caixa individuais - o valor em uso do ativo pode ser estimado por ser próximo do seu fair value menos os custos de venda e ofair value pode ser determinado.

O valor contábil líquido e o valor recuperável de uma UGC devem ser determinados sobre uma base consistente. A perda por impairment deve ser alocada para reduzir o valor contábil líquido dos ativos geradores de caixa de uma UGC em uma base pro rata, baseada no valor contábil líquido de cada ativo da UGC (Santos, Machado e Schmidt, 2003). 
Quando um ativo não gerador de caixa contribui para uma UGC, a proporção do valor contábil líquido desse ativo, efetuando o impairment test, é incluída no valor contábil líquido da UGC. Essa proporção reflete a extensão pela qual o potencial de serviço daquele ativo contribui para a UGC. A alocação de qualquer perda por impairment para a UGC então é feita numa base pro rata para todos os ativos geradores de caixa na UGC. O ativo não gerador de caixa deve ser testado para impairment de acordo com o Ipsas 21.

A reversão de uma perda por impairment para uma UGC deve ser alocada para os ativos geradores de caixa que a compõem em uma base pro rata do valor contábil líquido desses ativos. Esse aumento deve ser tratado como uma reversão da perda por impairment de ativos individuais. Nenhuma parte do valor da reversão deve ser alocada para ativos não geradores de caixa que contribuem com potencial de serviço da UGC.

Apesar da obrigatoriedade de cálculo anual do valor recuperável de um ativo intangível ainda não disponível para uso ou com vida útil indefinida, a estimativa mais recente desse valor, efetuada no período anterior, pode ser usada para o impairment test atual, desde que as suposições usadas não tenham mudado substancialmente.

Os seguintes elementos devem estar refletidos no cálculo do valor em uso: uma estimativa do fluxo de caixa futuro que a entidade espera obter do ativo; a possibilidade de variação do montante e do período do fluxo de caixa futuro; a taxa de juros livre de risco; o preço para suportar a incerteza inerente ao ativo e outros.

Para estimar o valor em uso de um ativo são necessárias duas etapas: estimar as entradas e saídas do fluxo de caixa futuro derivadas do contínuo uso do ativo e de seu valor final; e aplicar uma taxa apropriada de desconto sobre o fluxo de caixa futuro.

Geralmente, projeções do fluxo de caixa detalhadas e confiáveis são efetuadas para um período máximo de cinco anos. A entidade pode efetuar projeções de fluxos de caixa para um período superior a esse somente se elas forem confiáveis e se puder demonstrar isso por meio de experiência passada. Projeções de fluxos de caixa podem ser efetuadas até o final da vida útil do ativo por meio de extrapolação dessas projeções, utilizando-se taxas de crescimento. Esta taxa é fixa e declinante e, se apropriado, pode ser zero ou negativa.

O Ipsas 26 baseia-se no IAS 36 ao exigir que na estimativa do valor presente, por meio do fluxo de caixa, seja excluído o fluxo de caixa relacionado com o imposto, e consequentemente requerer o uso da taxa de desconto antes do imposto de renda. A justificativa do uso dessa taxa é evitar dupla contagem do fluxo de caixa tributário e simplificar o procedimento de desconto. Kvaal (2007) argumen- 
ta que embora definido que o uso tanto da taxa pré quanto da taxa pós-imposto de renda resulta no mesmo valor, a taxa pré é considerada mais simples e confiável. No entanto, uma apropriada taxa de desconto pré-imposto de renda varia entre ativos com diferentes estruturas e taxas de depreciação e que ela muda ao longo do tempo. Assim, a pré-taxa de desconto provavelmente se torna mais complexa. Esse autor aconselha o seguinte aperfeiçoamento nos padrões: o valor em uso deve ser mensurado por um fluxo de caixa após a tributação específica da empresa, e as taxas diferidas devem ser incluídas na revisão do impairment.

\section{Evidenciação - Gasb 42}

Segundo o Gasb 42, a perda por impairment deve ser evidenciada na demonstração de atividades e na demonstração de receitas, despesas e mudanças nos fundos líquidos de ativos, se apropriado, como um programa ou despesa operacional, item especial ou extraordinário. A perda por impairment apropriadamente divulgada como uma despesa do programa, geralmente deve ser divulgada como uma despesa direta do programa que usa ou usou o ativo de capital deteriorado. O quadro 6 apresenta um resumo do esquema de evidenciação da perda por impairment nas demonstrações financeiras.

Além disso, devem ser evidenciados em nota explicativa: uma descrição geral do montante e da classificação da perda por impairment; o valor do impairment do ativo de capital que está ocioso no final do exercício, independentemente de o impairment ser considerado permanente ou temporário; a quantia e a classificação da cobertura de seguros. Cabe destacar que a perda por impairment deve ser evidenciada líquida da cobertura de seguro quando ocorrem no mesmo ano.

Quadro 6

Resumo da abordagem de evidenciação da perda por impairment Gasb 42

\begin{tabular}{|llllll|}
\hline & \multicolumn{2}{c}{ Ativo fora de serviço } & & \multicolumn{2}{c|}{ Ativo ainda em serviço } \\
\cline { 2 - 3 } \cline { 5 - 6 } \cline { 5 - 6 } Balanço & Perda permanente & Perda temporária & & Mesma vida útil & Menor vida útil \\
\hline patrimonial contábil & Valor contábil & & Perda por & Perda por \\
& líquido ou fair & líquido & & impairment & impairment subtraída \\
& $\begin{array}{l}\text { value, dos dois o } \\
\text { menor }\end{array}$ & & & subtraída do valor & do valor contábil \\
& contábil líquido & & líquido \\
\hline
\end{tabular}

Continua 


\begin{tabular}{|c|c|c|c|c|}
\hline & \multicolumn{2}{|c|}{ Ativo fora de serviço } & \multicolumn{2}{|c|}{ Ativo ainda em serviço } \\
\hline & Perda permanente & Perda temporária & Mesma vida útil & Menor vida útil \\
\hline $\begin{array}{l}\text { Demonstração } \\
\text { de resultado }\end{array}$ & $\begin{array}{l}\text { Baixa para fair } \\
\text { value se necessário }\end{array}$ & $\begin{array}{l}\text { Suspender a } \\
\text { depreciação } \\
\text { até recuperar o } \\
\text { serviço }\end{array}$ & $\begin{array}{l}\text { Perda por } \\
\text { impairment líquida } \\
\text { da cobertura de } \\
\text { seguro }\end{array}$ & $\begin{array}{l}\text { Perda por } \\
\text { impairment líquida } \\
\text { da cobertura de } \\
\text { seguro }\end{array}$ \\
\hline
\end{tabular}

Fonte: Westly (2008: 8, tradução livre).

\section{Evidenciação — Ipsas 21 e 26}

A entidade deve evidenciar, para cada classe de ativo, o montante da perda por impairment e as reversões reconhecidas durante o período e a linha da demonstração financeira na qual o item foi incluído. Além disso, devem ser evidenciados para cada perda por impairment reconhecida ou revertida durante o período: os eventos e circunstâncias que conduziram o reconhecimento ou a reversão da perda; o montante da perda reconhecida ou revertida; a natureza do ativo; o segmento ao qual o ativo pertence, se a entidade evidenciar informações por segmento; se o valor recuperável é o fair value menos os custos de venda ou o valor em uso; se o valor recuperável é o fair value menos os custos de venda, a base usada para determinar esse valor (por exemplo, o valor de mercado); e se o valor recuperável é o valor em uso, o método usado para determiná-lo. A entidade deve ainda divulgar as principais suposições usadas para determinar o valor recuperável do ativo durante o período.

\section{Evidenciação - aspectos específicos do Ipsas 26}

No caso de perdas por impairment ou reversões dessas perdas para ativos geradores de caixa, a entidade deve evidenciar, além de todas as informações exigidas no Ipsas 21 , as informações especificadas nesta seção.

Em alguns casos não é claro se o objetivo primário do ativo de uma empresa é gerar retorno comercial. O julgamento é necessário para determinar se deve ser aplicado o Ipsas 26 ou o 21. Assim, a entidade deve evidenciar o critério utilizado para distinguir ativo gerador de caixa daqueles não geradores. Para cada perda por impairment reconhecida ou revertida, deve ser evidenciado:

v para o ativo gerador de caixa - a natureza do ativo e, se a entidade evidenciar informações por segmento, o segmento ao qual o ativo pertence; 
- para uma unidade geradora de caixa (UGC) — uma descrição da UGC (por exemplo, se é uma linha de produto, uma fábrica, uma operação comercial, uma área geográfica ou um relatório por segmento); o valor da perda por impairment reconhecida ou revertida por classe de ativo ou, se for o caso, por segmento; se a agregação de ativo por UGC mudar, uma descrição da atual UGC e as razões para as mudanças.

Evidenciar as estimativas usadas para mensurar o valor recuperável da UGC que contenha ativo intangível com vida útil indefinida. Quando o valor contábil líquido desse ativo, contido na UGC, é significante em comparação com o valor contábil líquido total dos ativos intangíveis com vida útil indefinida, a entidade deve evidenciar:

v o valor contábil líquido do ativo intangível com vida útil indefinida;

v as bases sobre as quais o valor recuperável do ativo foi determinado (isto é, valor em uso ou fair value menos custos para venda);

v se o valor recuperável é baseado no valor em uso, uma descrição das suposições usadas para as projeções do fluxo de caixa, o período sobre o qual foram efetuadas as projeções do fluxo de caixa, a taxa de crescimento usada para as projeções e a taxa de desconto aplicada nas projeções do fluxo de caixa;

- se o valor recuperável é baseado sobre o fair value menos os custos de venda, a metodologia usada para determiná-lo;

v se uma razoável mudança nas principais suposições utilizadas para estimar o valor recuperável da UGC fizer com que o valor contábil exceda o valor recuperável da UGC, a entidade deve evidenciar esse valor e os fatores que provocaram essa mudança;

- se alguns ou todos os valores contábeis dos ativos intangíveis com vida útil indefinida são alocados entre múltiplas UGCs, e o valor alocado para cada unidade não é significante em comparação com o valor contábil total dos ativos intangíveis com vida útil indefinida, este fato deve ser evidenciado, junto com o valor contábil líquido agregado dos ativos intangíveis com vida útil indefinida alocado àquelas unidades. Por outro lado, se o valor for significante, deve ser evidenciada também uma descrição das principais suposições utilizadas para determinar o valor recuperável. 


\section{Considerações finais}

Foram analisados quatro pronunciamentos sobre o impairment no setor público na pesquisa: o Gasb 42, os Ipsas 21 e 26 e a NBC T 16.10. Destaca-se que um confiável cálculo da perda por impairment depende do adequado reconhecimento e da mensuração dos ativos, inclusive com a contabilização da depreciação, amortização ou exaustão. Apesar da norma brasileira sobre o impairment no setor público já estar em vigor, muito ainda precisa ser feito em termos de reconhecimento e mensuração de ativos antes de sua aplicação, uma vez que os bens de uso comum, os especiais e a depreciação ainda não são contabilizados. A norma brasileira, NBC T 16.10, inclusive exige a realização do impairment test sem apresentar critérios para o processo de reconhecimento, mensuração e evidenciação da perda.

O Gasb 42 não trata do valor em uso e considera o custo de reposição como fair value. Por outro lado, para os Ipsas 21 e 26, o fair value é um valor de saída e o valor em uso é uma forma de verificar se o benefício oferecido pelo ativo quando em uso é maior ou menor do que aquele que pode ser obtido com a sua venda. Os métodos descritos no Gasb 42 para apurar o fair value são semelhantes aos descritos no Ipsas 21 para mensuração do valor em uso. Mesmo o Gasb 42 sendo restrito aos ativos de capital, a confrontação entre o valor em uso e o fair value seria útil.

O Ipsas 26 é o único pronunciamento aplicado aos ativos do setor público que utiliza a figura da unidade geradora de caixa (UGC). O subjetivismo envolvido na definição de uma UGC exige do profissional contábil uma dose elevada de responsabilidade e discernimento.

Os pronunciamentos apresentam uma relação não exaustiva de indicadores de impairment, sendo que se esses indicadores forem previsíveis, devem ser incorporados à depreciação e não representam impairment.

São descritas nos pronunciamentos as informações mínimas que devem ser evidenciadas sobre o processo de reconhecimento e mensuração da perda por impairment e, no caso dos Ipsas 21 e 26, da reversão dessa perda. No entanto, o profissional contábil deve evidenciar as informações que forem necessárias para informar ao usuário, de forma adequada, das demonstrações. O subjetivismo responsável é cada vez mais requerido, principalmente considerando que o Gasb 42 está alinhado com a postura do Fasb de estar mais voltado para uma filosofia baseada em princípios ao invés de regras.

Várias questões sobre a aplicação do impairment test no setor público permanecem sem resposta e ainda não foram discutidas na academia. Dessa forma, para pesquisas futuras, sugere-se: as normas sobre o impairment no setor públi- 
co são efetivas? Qual o critério de mensuração mais adequado para calcular o fair value de ativos imobilizados? Qual taxa é mais adequada para descontar o fluxo de caixa no cálculo do valor em uso de ativos geradores de caixa?

\section{Referências}

ALROY, Ron; TAL, Ran. Impairment of non-cash-generating assets. Israeli Professional Journal Roeh Haheshbon. 2005. Disponível em: <www.ifac.org/library/Article. tmpl?NID=11171220672200171 >. Acesso em: 20 ago. 2008.

ANONYMOUS. Official releases. Journal of Accountancy, v. 197, n. 2, p. 91-96, 2004.

BENSTON, George J.; BROMWICH, Michael; WAGENHOFER, Alfred. Principlesversus rules-based accounting standards: the Fasb's standard setting strategy. Abacus, v. 42, n. 2, 2006.

BRASIL. Lei no 4.320, de 17 de março de 1964. Estatui normas gerais de direito financeiro para elaboração e controle dos orçamentos e balanços da União, dos estados, dos municípios e do Distrito Federal. Disponível em: <www.planalto.gov. br/ccivil_03/LEIS/L4320.htm>. Acesso em: 20 nov. 2008.

. Lei no 10.406, de 10 de janeiro de 2002. Código civil. Disponível em: <www. planalto.gov.br/Ccivil_03/LEIS/2002/L10406.htm>. Acesso em: 20 out. 2008.

. Portaria no 184, de 25 de agosto de 2008. Ministério da Fazenda. Dispõe sobre as diretrizes a serem observadas no setor público (pelos entes públicos) quanto aos procedimentos, práticas, laboração e divulgação das demonstrações contábeis, de forma a torná-los convergentes com as normas internacionais de contabilidade aplicadas ao setor público. Disponível em: <www.fazenda.gov.br/portugues/legislacao/portarias/2008/ portaria184.asp >. Acesso em: 9 set. 2008.

CAPES (Coordenação de Aperfeiçoamento de Pessoal de Nível Superior). Qualis. Disponível em: < http://qualis.capes.gov.br/webqualis/ConsultaPeriodicos.faces>. Acesso em: 6 nov. 2008.

CFC (Conselho Federal de Contabilidade). Resolução CFC no 1.136, de 21 de novembro de 2008. Aprova a NBC T 16.9 - depreciação, amortização e exaustão. Disponível em: <www.cfc.org.br/sisweb/sre/docs/RES_1136.doc>. Acesso em: 26 nov. 2008a.

. Resolução CFC no 1.137, de 21 de novembro de 2008. Aprova a NBC T $\overline{16.10}$ - avaliação e mensuração de ativos e passivos em entidades do setor pú- 
blico. Disponível em: <www.cfc.org.br/sisweb/sre/docs/RES_1137.doc>. Acesso em: 30 nov. 2008b.

. Normas brasileiras de contabilidade aplicadas ao setor público elaboração e impacto. Seminários Regionais e Nacional. Disponível em: <www.cfc.org.br/ uparq/seminario_Region_Nacio.pdf $>$. Acesso em: 20 out. 2008c.

CHASE, B. W.; ROYARK, H. M. Hurricanes, tornadoes and other disasters: reporting their effect applying Gasb 42. Journal of Government Financial Management, p. 47-53, Summer 2006.

CVM (Comissão de Valores Mobiliários). Deliberação CVM nํㅜ 183, de junho de 1995. Aprova pronunciamento do Ibracon sobre reavaliação de ativos. Disponível em: <www.cvm.gov.br/asp/cvmwww/atos/exiato.asp?File=/deli/deli183.htm >. Acesso em: 14 ago. 2008.

FASB (Financial Accounting Standards Board). Concepts Statement $n^{\circ} 6$ - Elements of financial statements. 1985. Disponível em: <www.fasb.org/st/\#cons >. Acesso em: 25 out. 2008.

GASB 42. Accounting and financial reporting for impairment of capital assets and for insurance recoveries - nov. 2003. Disponível em: <www.gasb.org/st/summary/ gstsm42.html>. Acesso em: 9 set. 2008.

. Capital asset impairment and insurance recoveries — instructions. Disponível em: <www.gasb.br>. Acesso em: 9 set. 2008.

GAUTHIER, Stephen. Gasb issues new standard on capital asset impairments. Government Finance Review, p. 57-59, 2003.

GÖX, Robert F.; WAGENHOFER, Alfred. Optimal impairment rules. SSRN, 2008. Disponível em: <http://papers.ssrn.com/sol3/papers.cfm?abstract_id=1160166>. Acesso em: 14 ago. 2008.

HENDRIKSEN, E. S.; VAN BREDA, M. Teoria da contabilidade. São Paulo: Atlas, 1999.

IASB (International Accounting Standards Board). IAS 36 - impairment of assets. June 1998.

IFAC (The International Federation of Accountants). International public sector accounting standard Ipsas 21 - impairment of non-cash-generating assets. Dec. 2004. Disponível em: <www.ipsas.org/PDF_ipsas_standards_ifac/2006_A25_IPSAS_ 21.pdf>. Acesso em: 14 ago. 2008.

. International public sector accounting standard Ipsas 26 - impairment of cash-generating assets. Feb. 2008. Disponível em: <www.ifac.org/Members/Pubs- 
Details.tmpl?PubID=12027455151185165\&Category=Public\%20Sector\%20Acco unting >. Acesso em: 14 ago. 2008.

IUDÍCIBUS, Sérgio de; MARION, José Carlos; PEREIRA, Elias. Dicionário de termos de contabilidade. 2. ed. São Paulo: Atlas, 2003.

; MARTINS, Eliseu. Uma investigação e uma proposição sobre o conceito e o uso do valor justo. Revista Contabilidade \& Finanças, São Paulo, ed. 30 Anos de Doutorado, p. 9-18, jun. 2007.

KVAAL, Erlend. Discounting and the treatment of taxes in impairment reviews. Journal of Business Finance \& Accounting, v. 34 n. 5-6, p. 767-791, June/July 2007.

LOCK, Fernando do Nascimento; PIGATTO, José A. Magrini. A dificuldade de alinhamento entre a contabilidade pública brasileira e o government finance statistics - GFS. Revista Eletrônica de Contabilidade da UFSM, v. 1, n. 3, 2005.

MACÊDO, Maurício Ferreira de. Impacto das normas internacionais de contabilidade na apresentação das demonstrações contábeis. In: CONFERÊNCIA INTERAMERICANA DE CONTABILIDADE, 25., 2003. Panamá. Anais eletrônicos... Disponível em: $<$ www.auditar.org.br/upimgs/pdf/Artigo\%20Mauricio\%20Ferreira.pdf > . Acesso em: 20 set. 2008.

NASCIMENTO, Leonardo Silveira do. A reforma da contabilidade governamental brasileira: a necessária revisão dos preceitos vigentes em face das demandas de informações e do esforço de harmonização nacional e internacional. Brasília: Esaf, 2007. Disponível em: <www.tesouro.fazenda.gov.br/premio_TN/XIIPremio/ sistemas/3tosiXIIPTN/a_reforma_da_contabilidade_governamental.pdf $>$. Acesso em: 20 out. 2008.

PIGATTO, José Alexandre Magrini. Estudo comparativo dos regimes contábeis governamentais. 2004. 200 f. Dissertação (Mestrado em Ciências Contábeis) — Programa de Pós-Graduação em Ciências Contábeis, Departamento de Contabilidade e Atuária, Faculdade de Economia, Administração e Contabilidade da Universidade de São Paulo, São Paulo.

RAUPP, Fabiano Maury; BEUREN, Ilse Maria. Proposta de Mensuração de Ativos Imobilizados por Meio do Fair Value e do Impairment Test. In: CONGRESSO USP DE CONTROLADORIA E CONTABILIDADE, 6., 2006. Anais... São Paulo: USP, 2006, CD-Rom.

ROBBINS, Walter; BALDWIN, Amelia. Gasb 34: new requirements for general capital assets. CPA Journal. 2002. Disponível em: < http://findarticles.com/p/articles/mi_qa5346/is_/ai_n21319533>. Acesso em: 20 out. 2008. 
SANTOS, José Luiz dos; MACHADO, Nilson Perinazzo; SCHMIDT, Paulo. Teste de impairment para ativos de longa duração: tratamento contábil de acordo com o SFAS no 144. Contexto, Porto Alegre, v. 3, n. 5, p. 99-121, 2003.

SEC (Securities and Exchange Commission). Study Pursuant to Section 108(d) of the Sarbanes-Oxley Act of 2002 on the adoption by the United States Financial Reporting System of a principles-based accounting system. July 2003. Disponível em: <www. sec.gov/news/studies/principlesbasedstand.htm >. Acesso em: 20 out. 2008.

SILVA, Paula Danyelle Almeida da et al. Impairment de ativos de longa duração: comparação entre o SFAS 144 e o IAS 36. In: CONGRESSO USP DE CONTROLADORIA E CONTABILIDADE, 6., 2006. Anais... São Paulo: USP, 2006, CD-Rom.

WATTS, Ross L. Conservatism in accounting part I: explanations and implications. Accounting Horizons, v. 17, n. 3, p. 207-221, 2003.

WESTLY, Steve. Gasb no 42, accounting and financial reporting for impairment of capital assets and for insurance recoveries intructions. California State Controller. Division of Accounting and Reporting. Disponível em: <www.sco.ca.gov/ard/state/ gasb42instr.pdf>. Acesso em: 20 ago. 2008.

WIELENBERG, Stefan; SCHOLZE, Andreas. Depreciation and impairment: a tradeoff in a stewardship setting. SSRN. 2007. Disponível em: http://papers.ssrn.com/sol3/ papers.cfm?abstract_id=996554. Acesso em: 20 ago. 2008. 